\title{
Evaluation of extracellular polymeric substances extracted from waste activated sludge as a renewable corrosion inhibitor
}

\author{
Liew Chien Go ${ }^{1}$, William Holmes ${ }^{2}$, Dilip Depan ${ }^{1}$, Rafael Hernandez ${ }^{\text {Corresp. } 1}$ \\ ${ }^{1}$ Department of Chemical Engineering, University of Louisiana at Lafayette, Lafayette, Louisiana, United States \\ 2 Energy Institute of Louisiana, University of Louisiana at Lafayette, Lafayette, Louisiana, United States \\ Corresponding Author: Rafael Hernandez \\ Email address: rhernandez@louisiana.edu
}

Background. Waste activated sludge (WAS) has recently gained attention as a feedstock for resource recovery. The aim of this study is to investigate the corrosion inhibition efficiencies of extracellular polymeric substances (EPS) extracted from WAS.

Methods. The studied corrosion inhibitors were tested with carbon steel in $3.64 \% \mathrm{NaCl}$ saturated with $\mathrm{CO}_{2}$ at $25^{\circ} \mathrm{C}$, which is the typical oilfield environment. They were first prepared by EPS extraction (heating at $80^{\circ} \mathrm{C}$ ), followed by centrifugation for solid and liquid separation, then the supernatant was freeze-thawed five times for sterilization of microorganisms in WAS to terminate metabolic activities in the test inhibitors to ensure consistency in corrosion inhibition. The EPS mixture (supernatant) was then deemed as the test corrosion inhibitor. The inhibition performance was determined using potentiodynamic polarization scans.

Results. WAS alone showed unsatisfactory inhibition. However, EPS extracted from WAS showed an optimum inhibition of approximately $80 \%$ with $1000 \mathrm{mg} / \mathrm{L}$ of inhibitor. The average total solid (TS) and EPS contents of the WAS were $7330 \mathrm{mg}$ TS/L WAS and $110 \mathrm{mg}$ EPS/g TS, respectively. Three sets of extracted EPS were scanned with FTIR and showed almost overlapping curves, yielding the consistent inhibition performance.

Discussion. The potentiodynamic polarization results indicated that EPS acts as a mixed-type inhibitor which inhibits corrosion on both anode and cathode sites of metal surfaces. Based on the FTIR results, it was assumed that major chemical groups $\mathrm{O}-\mathrm{H}, \mathrm{N}-\mathrm{H}, \mathrm{C}-\mathrm{N}, \mathrm{C}=\mathrm{O}$, and $\mathrm{C}-\mathrm{H}$ contributed to the inhibition by adsorbing on the metal surface, forming a biofilm that acts as a protective barrier to isolate the metal from its corrosive environment. Results show that WAS EPS corrosion inhibitors have inhibition performance comparable to commercial products, signifying their potential in commercialization. This corrosion inhibitor is renewable, biodegradable, non-toxic, and free from heavy metal, making it a superior green corrosion inhibitor candidate. Additionally, turning biomass into value-added product can be beneficial to the environment and, in this case, deriving new materials from WAS could also transform the economics of wastewater treatment operations. 


\section{Evaluation of extracellular polymeric substances}

2 extracted from waste activated sludge as a renewable

3 corrosion inhibitor

4

Liew Chien Go ${ }^{1}$, William Holmes ${ }^{2}$, Dilip Depan ${ }^{1}$, Rafael Hernandez ${ }^{1}$

${ }^{1}$ Department of Chemical Engineering, University of Louisiana at Lafayette, Lafayette, LA, 8 United States

$9{ }^{2}$ Energy Institute of Louisiana, University of Louisiana at Lafayette, Lafayette, LA, United 10 States

11

12

Corresponding Author:

Rafael Hernandez ${ }^{1}$

131 Rex Street, Lafayette, LA, 70504, United States

Email address: rhernandez@louisiana.edu

\section{Abstract}

Background. Waste activated sludge (WAS) has recently gained attention as a feedstock for resource recovery. The aim of this study is to investigate the corrosion inhibition efficiencies of extracellular polymeric substances (EPS) extracted from WAS.

Methods. The studied corrosion inhibitors were tested with carbon steel in $3.64 \% \mathrm{NaCl}$ saturated with $\mathrm{CO}_{2}$ at $25^{\circ} \mathrm{C}$, which is the typical oilfield environment. They were first prepared by EPS extraction (heating at $80^{\circ} \mathrm{C}$ ), followed by centrifugation for solid and liquid separation, then the supernatant was freeze-thawed five times for sterilization of microorganisms in WAS to terminate metabolic activities in the test inhibitors to ensure consistency in corrosion inhibition. The EPS mixture (supernatant) was then deemed as the test corrosion inhibitor. The inhibition performance was determined using potentiodynamic polarization scans.

Results. WAS alone showed unsatisfactory inhibition. However, EPS extracted from WAS showed an optimum inhibition of approximately $80 \%$ with $1000 \mathrm{mg} / \mathrm{L}$ of inhibitor. The average total solid (TS) and EPS contents of the WAS were $7330 \mathrm{mg}$ TS/L WAS and $110 \mathrm{mg}$ EPS/g TS, respectively. Three sets of extracted EPS were scanned with FTIR and showed almost overlapping curves, yielding the consistent inhibition performance.

Discussion. The potentiodynamic polarization results indicated that EPS acts as a mixed-type inhibitor which inhibits corrosion on both anode and cathode sites of metal surfaces. Based on the FTIR results, it was assumed that major chemical groups $\mathrm{O}-\mathrm{H}, \mathrm{N}-\mathrm{H}, \mathrm{C}-\mathrm{N}, \mathrm{C}=\mathrm{O}$, and $\mathrm{C}-\mathrm{H}$ contributed to the inhibition by adsorbing on the metal surface, forming a biofilm that acts as a protective barrier to isolate the metal from its corrosive environment. Results show that WAS EPS corrosion inhibitors have inhibition performance comparable to commercial products, signifying their potential in commercialization. This corrosion inhibitor is renewable, 
40 biodegradable, non-toxic, and free from heavy metal, making it a superior green corrosion

41 inhibitor candidate. Additionally, turning biomass into value-added product can be beneficial to

42 the environment and, in this case, deriving new materials from WAS could also transform the

43 economics of wastewater treatment operations.

44

\section{Introduction}

46 The United States Environmental Protection Agency (EPA) is urging wastewater treatment 47 facilities to be viewed as Renewable Resource Recovery Facilities that produce clean water, 48 recover energy, and generate nutrients [1]. Efforts on energy recovery such as waste incineration 49 and/or biogas production using anaerobic digestion are in practice at many wastewater treatment 50 plants in the nation. However, further research is needed on the recovery of resources and 51 nutrients using the biomass produced from wastewater treatment facilities. The Water 52 Environment Federation believes that wastewater treatment plants are not just waste disposal

53 facilities, but rather water resource recovery facilities that produce clean water and recover nutrients [2]. These facilities carry an array of high carbon sources as well as nutrients such as nitrogen and phosphorus-based compounds. By recovering these biomasses to value-added products, such facilities have a high potential to reduce the nation's dependence on fossil fuels through the production and use of renewable bioproducts. A great number of potentially marketable products could be recovered from the same facilities. Some value-added products derived from wastewater have been studied, like biodiesel, biodegradable plastics, adhesives, and enzymes useful in biomedical applications [1].

Activated sludge is a common secondary treatment process for domestic and industrial wastewaters. This process is based on organics degradation by microorganisms under aerobic conditions. Carbons are used by the microorganisms to synthesize new cells or derive energy, leaving a relatively clear effluent. Some of the microorganisms are recycled to the aeration tank as a way of controlling the solids' residence time, while a fraction of the microorganisms is wasted and labeled as waste activated sludge (WAS). Millions of tons of this material are wasted annually by wastewater treatment operations. Extracellular polymeric substances (EPS) are the metabolic products produced by microorganisms that accumulate on their surface, forming slimy layers of biofilm. They are generally used to protect the cells against their external environment and to serve as carbon and energy reserves during starvation [3].

Studies on the generation of new materials like corrosion inhibitors by microorganisms are relatively scarce as compared to other green phytochemical-based corrosion inhibitors generated from agricultural residues. Pure cultures of sulfate-reducing bacteria, Pseudomonas [4], Pseudomonas putida, and Pseudomonas mendocina KR1 [5] have been tested and showed potential in corrosion inhibition. In the presence of some of these bacteria, with capability of developing biofilm to various degrees, it was observed that the mass loss of the tested metal can be decreased up to 15-fold. A similar study on sewage sludge extracted amino acids suggested 
80

81

82

83

84

85

86

87

88

89

90

91

92

93

94

95

96

97

98

99

100

101

102

103

104

105

106

107

108

109

110

111

112

113

114

115

116

117

118

the potential of sludge as a feedstock for corrosion inhibitor production [6]. Other recent studies

have shown that EPS can adsorb heavy metals for the purpose of water treatment [7][8], showing that EPS possess distinct metal ion binding capability.

This study hypothesized that the metal binding characteristics of EPS can also act as a corrosion inhibitor when this EPS is extracted from WAS. Since WAS is a readily available waste biological material source of wastewater treatment operations, extracting EPS directly from WAS can transform this waste biomass into a valuable product and reduce the environmental management challenge of WAS disposal.

As mentioned above, the hypothesis of this study is that a corrosion inhibitor can be made with EPS extracted from WAS. EPS can bind with the metal to form a biofilm layer on the metal surface to isolate the metal from its corrosive surroundings, thus promoting corrosion inhibition. To our knowledge, there are no previous studies in the peer reviewed literature on the evaluation of EPS extracted from WAS as a corrosion inhibitor. The objective of this study was to investigate the performance of WAS extracted EPS as an oilfield corrosion inhibitor. Oil field conditions were simulated using carbon steel in $3.64 \%$ sodium chloride solution saturated with carbon dioxide gas using a potentiodynamic polarization technique. EPS was extracted by heating, using techniques described elsewhere [9][10].

\section{Materials \& Methods}

Metal specimen preparation

Potentiodynamic polarization scans were performed on carbon steels of the following weight percentage composition: $0.17 \mathrm{C}, 0.08 \mathrm{Mn}, 0.014 \mathrm{P}, 0.002 \mathrm{~S}, 0.022 \mathrm{Si}, 0.02 \mathrm{Cu}, 0.01 \mathrm{Ni}, 0.04 \mathrm{Cr}$, $0.002 \mathrm{Sn}, 0.042 \mathrm{Al}, 0.006 \mathrm{~N}, 0.001 \mathrm{~V}, 0.0001 \mathrm{~B}, 0.001 \mathrm{Ti}, 0.001 \mathrm{Cb}$, and the remainder iron. The pre-treatment of the specimens' surface was carried out by grinding with sand papers of 40, 220, 320 grits, rinsing with deionized water, and drying with paper towel. The specimens were used right away after the pre-treatment.

\section{Corrosive medium preparation}

The test solution $3.64 \%$ of $\mathrm{NaCl}$ was used in the experiments. These solutions were prepared using deionized water and $\mathrm{NaCl}$ (Fisher Scientific). Prior to initiating each experiment, $\mathrm{CO}_{2}$ was sparged at $207 \mathrm{kPa}(30 \mathrm{psi})$ in the test solution for 30 minutes. Then, the solution was transferred to the reactor and $\mathrm{CO}_{2}$ sparging continued over the remainder of the experiment at about $138 \mathrm{kPa}$ (20 psi).

\section{WAS samples processing}

All WAS samples used for this study were collected from the recirculation stream of the aeration basins of East Wastewater Treatment Plant, Lafayette, LA 70501, USA. Three total samples 
119 were collected on three different days, i.e., June $22^{\text {nd }}$, June $30^{\text {th }}$, and July $2^{\text {nd }}$ of 2016 , in order to

120 reduce bias from variation of wastewater.

121

122

123

124

125

126

127

128

129

130

131

132

133

134

135

136

137

138

139

140

141

142

143

144

145

146

147

148

149

150

151

152

153

154

155

156

157

158
The WAS samples collected from each sampling day were divided into two groups. The first group of samples were used for corrosion inhibitor preparation, while the second group of samples were used for the quantification of WAS total solid and EPS.

Corrosion inhibitors preparation

All WAS samples were concentrated by removing $80 \%$ of the water. The WAS samples were processed using two different methods in this study as control and test corrosion inhibitors. Hence, they were separated into two batches according to their processing method. Control experiments were done without EPS extraction, while EPS was extracted and tested as corrosion inhibitors.

Control experiments: WAS as corrosion inhibitors

A Welch Dry Fast Ultra Diaphragm Pump 2032 vacuum pump was used to evaporate $80 \%$ of the water from the WAS samples at room temperature, followed by centrifugation for 5 minutes at a relative centrifugal force $(\mathrm{RCF})$ of $1207 \times \mathrm{g}$ with a Thermo Scientific ${ }^{\mathrm{TM}}$ Sorvall ${ }^{\mathrm{TM}}$ ST 40

Centrifuge Series. The solid part was discarded, while all supernatants were collected and frozen for 24 hours at $-20^{\circ} \mathrm{C}$, then thawed for another 24 hours. The freeze-thaw process was repeated five times to terminate the metabolic activities of the microorganisms. Then, the supernatant was used as a potential corrosion inhibitor.

\section{Corrosion inhibitor testing experiments: EPS as corrosion inhibitors}

The WAS samples were heated at $80^{\circ} \mathrm{C}$ and stirred at $600 \mathrm{rpm}$ using a Fisher Scientific ${ }^{\mathrm{TM}}$ Isotemp ${ }^{\mathrm{TM}}$ Digital Stirring Hotplate. The samples were heated for EPS extraction and to evaporate $80 \%$ of water from the WAS samples. Heating is a physical method of EPS extraction. Furthermore, the relatively low temperature of heating minimizes the degradation of temperature labile compounds. Samples were then cooled down to room temperature and centrifuged at 1207 $\times \mathrm{g}$ for 5 minutes. Then, the supernatant was collected and frozen for 24 hours at $-20^{\circ} \mathrm{C}$, followed by thawing for another 24 hours. The freeze-thaw process was repeated five times before the supernatant was deemed as an EPS mixture for corrosion inhibition testing.

Quantification of WAS total solid (TS) and EPS contents

WAS samples were also used for quantification of TS content and EPS. Samples for TS content quantification were placed in ten $50 \mathrm{~mL}$ Corning centrifugal tubes. These tubes were centrifuged at $1207 \times \mathrm{g}$ for 5 minutes. Then, the supernatant was discarded. The solid left in the tubes was frozen at $-20^{\circ} \mathrm{C}$ overnight. The frozen solid was freeze-dried for 24 hours using a Labconco freeze dryer at $-80^{\circ} \mathrm{C}$ and approximately $0 \mathrm{~Pa}$. The dried solid was then weighed. The TS content was calculated based on the total weight of dried solid divided by $0.5 \mathrm{~L}$ of WAS.

Peer] reviewing PDF | (2019:03:35697:1:0:NEW 2 May 2019) 
159

160

161

162

163

164

165

166

167

168

169

170

171

172

173

174

175

176

177

178

179

180

181

182

183

184

185

186

187

188

189

190

191

192

193

194

195

196

197
For EPS quantification, a total of $500 \mathrm{~mL}$ WAS was divided into two $250 \mathrm{~mL}$ beakers. Both beakers were heated at $80^{\circ} \mathrm{C}$ and stirred at $600 \mathrm{rpm}$ for EPS extraction and to evaporate $80 \%$ of the water in the beakers. Separating WAS into two smaller containers and constant stirring were done to ensure even heating. These solutions were then combined, cooled down to room temperature, and centrifuged at $1207 \times \mathrm{g}$ for 5 minutes. The supernatant was collected in a 400 $\mathrm{mL}$ beaker and $100 \mathrm{~mL}$ of chilled ethanol $\left(-20^{\circ} \mathrm{C}\right)$ was added. The precipitate, EPS, was filtered out from the solution, dried, and then weighed. The quantity of EPS was calculated based on the weight of the dried EPS divided by $0.5 \mathrm{~L}$ of WAS, as well as the weight of dried EPS divided by dried solid in 0.5 L of WAS.

\section{Potentiodynamic polarization method}

Potentiodynamic polarization experiments were carried out with a Gamry Flexcell Critical Pitting Cell Kit, connected to a Gamry Potentiostat Interface 1000. The reference, counter, and working electrodes used were saturated calomel electrode (SCE), graphite rod, and the metal specimen, respectively. The setup was equipped with a heating jacket connected to a TDC4 Omega temperature controller to maintain the test solution at a desired temperature of $25^{\circ} \mathrm{C}$. The Glas-Col GT Series stirrer was connected to the setup externally and adjusted to $50 \mathrm{rpm}$ to get the desired shear and to ensure even heating. The working solution volume was $1 \mathrm{~L}$. The working area of the metal specimens had a circular form of $5 \mathrm{~cm}^{2}$.

The potentiodynamic polarization scans were carried out in the potential range of -0.25 to +0.25 $\mathrm{V}$ versus corrosion potential $\left(\mathrm{E}_{\text {corr }}\right)$ at a scan rate of $3 \mathrm{~V} / \mathrm{hr}$. Corrosive medium was added into the reactor with $\mathrm{CO}_{2}$ sparging constantly at $138 \mathrm{kPa}(20 \mathrm{psi})$ throughout the experiment. The reactor was equilibrated for 30 minutes prior to the beginning of experiment. After the system was equilibrated, Tafel plots were graphed with Gamry DC105 DC Corrosion Technique Software until three relatively similar readings were obtained. Next, corrosion inhibitor was added into the reactor. The reactor was again allowed to equilibrate for 30 minutes, then Tafel plots were graphed. This step was repeated until three consecutive graphs with similar trends were observed to ensure the stability of the system.

The Tafel plot was plotted with the mean values of corrosion potential $\left(\mathrm{E}_{\mathrm{corr}}\right)$ and corrosion current density ( $\left.\mathrm{I}_{\text {corr }}\right)$ from the triplicates of the experiments, while the electrochemical parameters obtained from the curves were reported with mean and standard deviation. The corrosion current densities were found by extrapolating the linear Tafel segment of the anodic and cathodic curves to the corrosion potential. The corrosion inhibition efficiency was then calculated with:

Inhibition Efficiecny (\%) $=\frac{I_{\text {corr, uninhibited }}-I_{\text {corr, inhibited }}}{I_{\text {corr, }, \text { uninhibited }}} \times 100 \%$ 
198 Fourier-transform infrared spectroscopy (FTIR)

199 Agilent Cary 630 FTIR incorporated with MicroLab software were used for the FTIR analysis in

200 this study. This equipment worked based on the Attenuated Total Reflection (ATR) Method. The

201 scanning was ranged between 4000 to $400 \mathrm{~cm}^{-1}$ with resolution of $4 \mathrm{~cm}^{-1}$.

202

203

\section{Results}

204 Control experiments: WAS as corrosion inhibitors

205 The Tafel plot obtained for this concentrated WAS is shown in Figure 1. The electrochemical

206 parameters obtained from the Tafel plot such as the values of corrosion potential, $\mathrm{E}_{\text {corr }}$, corrosion

207 current density, $\mathrm{I}_{\text {corr }}$, and corrosion protection efficiency are presented in Table 1.

208

209 Corrosion inhibitor testing experiments: EPS as corrosion inhibitors

210 Tafel curves generated from the potentiodynamic polarization measurements for carbon steel in

$2113.64 \% \mathrm{NaCl}$ saturated with $\mathrm{CO}_{2}$ in the absence and presence of some concentrations of test

212 inhibitor at $25^{\circ} \mathrm{C}$ are presented in Figure 2. The details of electrochemical parameters obtained

213 from the curves, namely corrosion potential $\left(\mathrm{E}_{\text {corr }}\right)$, corrosion current density $\left(\mathrm{I}_{\text {corr }}\right)$, and inhibition

214 efficiency, are listed in Table 2.

215

216 Total solid (TS) and EPS contents

217 TS and EPS contents in WAS were quantified, and the results are summarized in Table 3. TS

218 quantification was conducted before EPS extraction. The standard deviation was relatively low

219 which demonstrates the reproducibility of the experimental procedures and consistency of WAS

220 composition.

221

222 FTIR

223 The extracted white powder from WAS, assumed to be EPS at the time of the corrosion

224 inhibition studies, was examined using FTIR, as shown in Figure 3. Although the WAS samples

225 were collected from three different days, the FTIR curves of the EPS followed similar trends.

226 This uniform EPS FTIR results explain the consistency of corrosion protection performance (low

227 standard deviation values). The characteristic absorption of IR was tabulated in Table 4 . These

228 data were compared to a previous study on EPS extracted from WAS [9][10]. The functional

229 groups of several major compounds typically found in EPS were also identified, i.e. O-H, N-H,

$230 \mathrm{C}-\mathrm{N}, \mathrm{C}=\mathrm{O}$, and $\mathrm{C}-\mathrm{H}$ groups.

231

232 Discussion

233 Control experiments: WAS as corrosion inhibitors

234 The objective of utilizing WAS as a control was to examine a concentrated solution of

235 compounds containing atoms of interest for corrosion inhibition. In the Tafel plot, it can be

236 observed that the curves are very close to each other, regardless of the increase in the

237 concentration of WAS (potential corrosion inhibitor). Table 1 clearly demonstrates that $\mathrm{I}_{\text {corr }}$ 
238

239

240

241

242

243

244

245

246

247

248

249

250

251

252

253

254

255

256

257

258

259

260

261

262

263

264

265

266

267

268

269

270

271

272

273

274

275

276

277

values are not impacted by the WAS concentration, and consequently inhibition efficiency. Increasing WAS concentrations from 0 to a $1000 \mathrm{mg} / \mathrm{L}$ did not change $\mathrm{I}_{\text {corr }}$. The data clearly indicate that the WAS tested did not contain compounds capable of inhibiting corrosion. Changes were so small that it was difficult to precisely measure corrosion inhibition. This difficulty resulted in relatively large and inconsistent standard deviations. The unsatisfactory results from both $\mathrm{I}_{\text {corr }}$ and $\mathrm{E}$ revealed that WAS was not suitable to be used as a corrosion inhibitor, rendering the value of $\mathrm{E}_{\text {corr }}$ meaningless. Therefore, it can be deduced that the supernatant of WAS is not an effective corrosion inhibitor because of the absence or extremely diluted corrosion inhibitive compounds, making analysis for chemical oxygen demand (COD) unimportant. The supernatant was tested as a control to demonstrate the effectiveness and significance of the EPS extraction and performance as corrosion inhibitor.

Corrosion inhibitor testing experiments: EPS as corrosion inhibitors

The curves revealed well defined anodic and cathodic polarization Tafel regions. From Figure 2, it can be observed that both anodic and cathodic branch of polarization curves shift to lower values of current density as compared to the blank. This phenomenon indicated inhibition of both the hydrogen evolution and metal dissolution reactions [11]. This may be ascribed to adsorption of inhibitor over the corroded surface [12]. The corrosion inhibition mechanism of EPS is often described by: (1) the formation of a protective passive layer on metal the surface, (2) the depletion of oxygen by the metabolism of microorganisms, and (3) growth inhibition of corrosion-causing microbes, for example, from antimicrobial production by non-corrosive microorganisms; in multispecies biofilm, a combination of the different mechanisms may occur [4][5][16][17]. However, based on the results of $E_{\text {corr, }}$ the corrosion inhibition mechanism of EPS in this study can be described by the formation of a protective passive layer (EPS biofilm) on the metal surface. There was no definite trend observed in $\mathrm{E}_{\text {corr }}$ values in the presence of different concentrations of WAS in the experiments. This result indicated that the WAS may be regarded as a mixed type corrosion inhibitor [13] in presence of $\mathrm{CO}_{2}$ saturated $3.64 \% \mathrm{NaCl}$ solutions. Also, the maximum displacement in $\mathrm{E}_{\text {corr }}$ of less than $0.085 \mathrm{~V}$ suggests the mixed mode of inhibition [14]. Mixed type corrosion inhibitor suppresses both anodic and cathodic corrosion reactions, typically indicating that the inhibitor adsorbed on the metal surface, forming a film to isolate the metal surface from the corrosive environment [15]. The application of EPS for the purpose of mitigating metal corrosion has been evaluated by other investigators [4][5]. However, to our knowledge this is the first study evaluating EPS from a mixed microbial consortium (e.g., WAS), considered a waste and generated at millions of tons levels annually.

The maximal inhibition protection was $78.89 \%$ at a concentration of $1000 \mathrm{mg} / \mathrm{L}$. The inhibitor mixture was freeze-thawed at $-20^{\circ} \mathrm{C}$ five times to stop metabolic activity. At a temperature of $2{ }^{\circ} \mathrm{C}$, microbial growth can be stopped, and susceptible organisms can be killed [18]. Elimination of microbial activity ensures a stable composition of the test solution. In the literature, research works have been conducted on utilizing the EPS of pure cultures of microorganisms as corrosion 
278 inhibitors for SAE 1018 in synthetic brine. Microorganisms such as Rhizobium meliloti 102F34, 279 Streptomyces lividans TK23.1, and Bacillus circulans were grew with the metal coupons for a 280 week. They showed corrosion inhibitions of $88 \%, 82 \%$, and $73 \%$ corrosion inhibition, 281 respectively [5]. A similar study utilizing WAS extracted amino acids showed $94 \%$ of inhibition 282 when $372 \mathrm{mg} / \mathrm{L}$ of inhibitor was applied [6]. Amino acids are only a small fraction of the overall 283 EPS composition. EPS is a mixture of extracellular proteins, polysaccharides, humic substances,

284

285

286

287

288

289

290

291

292

293

294

295

296

297

298

299

300

301

302

303

304

305

306

307

308

309

310

311

312

313

314

315

316 uronic acid and DNA. The amino acids in the extracellular proteins of EPS could have contributed to the corrosion inhibition. The presence of other compounds could have interfered with corrosion inhibition by adsorbing weakly on the metal surface or serving as a barrier (stearic hindrance) for the adsorption of chemical groups responsible for inhibition. Future studies will focus on the preparation of a mixture based specifically on the EPS groups that are known to perform as corrosion inhibitors.

For the case of commercial corrosion inhibitors, their corrosion protection performances are typically above $70 \%$. Corrosion inhibitors developed from WAS have a corrosion inhibition performance that is within the range of commercial corrosion inhibitors. One advantage compared to pure culture investigations is that WAS is a readily available source in the wastewater treatment operations and does not require sterile conditions. The results obtained from this study strongly suggest the great potential of transforming WAS into a valuable material to inhibit corrosion issues in oil field operations.

Furthermore, turning waste to value-added products can benefit the environment, society, and the economy. Instead of treating wastewater for waste management, value-added products such as corrosion inhibitors can be extracted from these readily available sources, transforming wastewater treatment operations into resource recovery units instead of sending WAS to the landfill or, even worse, incineration.

Total solid (TS) and EPS contents

TS in WAS refers to all present solids. It is the residue remaining upon evaporation of WAS under $103^{\circ} \mathrm{C}$. The freeze-dry method was applied in this study to minimize the effect of heat during sample evaporation and prevent the loss of volatile solids.

EPS can be extracted from WAS by two means: chemical and physical methods. Some examples of chemical methods include the usage of EDTA, formaldehyde with $\mathrm{NaOH}$, and glutaraldehyde; physical methods include heating, sonication, cation exchange resin, sonication with cation exchange resin, and centrifugation [9][10][19]. Typically, chemical methods give higher yield of EPS as compared to physical methods. However, a study by infrared analysis showed that chemicals used for extraction can contaminate the mixture of EPS [10]. Therefore, chemical extraction was not considered in this study. Heating at $80^{\circ} \mathrm{C}$ was chosen in this study because it

Peer) reviewing PDF | (2019:03:35697:1:0:NEW 2 May 2019) 
317 is a well-established EPS extraction method in the literature. This temperature is considered mild 318 for EPS extraction, preventing the degradation of EPS.

319

320

321

322

323

324

325

326

327

328

329

330

331

332

333

334

335

336

337

338

339

340

341

342

343

344

345

346

347

348

349

350

351

352

353

354

355

Even if the same extraction method is applied, the variation in sample preparation and modification in experimental procedure can also greatly affect the yield of EPS. For instance, by practicing heating extraction, some researchers extract EPS using raw WAS without any sample processing, while some researchers dry the WAS followed by resuspending the dried sludge solid in saline or water before EPS extraction. In addition, some researchers extract the EPS (heat) for 10 minutes, while some do it for hours.

Many studies report EPS content using different bases, such as mixed liquor suspended solid (MLSS) and volatile suspended solid (VSS). The range of EPS content can be tens to hundreds of $\mathrm{mg}$ EPS/g MLSS and mg EPS/g VSS. The EPS content found from this study was $110 \mathrm{mg}$ EPS/g TS. Comte et al. extracted two batches of WAS EPS resulting in averages of $62 \mathrm{mg}$ EPS/g VSS and $64 \mathrm{mg}$ EPS/g VSS [9][10]. Liu et al. also extracted WAS EPS resulting in an average of $58 \mathrm{mg}$ EPS/g VSS [19]. Since the units are inconsistent, comparison of the EPS quantity can be difficult. Furthermore, EPS content in WAS is dependent on the wastewater facility operating conditions. However, knowing that VSS is typically about $78 \%$ of TS [20], it can be estimated that the EPS content obtained from this study was about $86 \mathrm{mg}$ EPS/g VSS. This estimate is about $25 \%$ compared to the literature. This could have been caused by the longer EPS extraction time. In general, the extraction time of other studies is approximately 30 minutes. We extracted EPS for 6 hours, until $80 \%$ of the liquid from WAS was evaporated.

The compositions of WAS and EPS could vary due to wastewater treatment operating conditions and weather. Considering that WAS samples were only collected during summer, the TS and EPS contents were notably consistent. Since this study is a proof of concept to investigate if WAS EPS can act as a potential corrosion inhibitor, several other factors that can affect the WAS and EPS were not considered. For example, WAS seasonal variations or verification of microbial metabolic activity. Future work will focus on formulating a synthetic EPS mixture with known chemical compounds. The composition of natural EPS will be used as a basis. The hypothesis is that the new corrosion inhibitor formulation can act similarly or better to the studied natural EPS. By doing so, the variability in wastewater can be eliminated in addition to having a better understanding of the inhibition mechanism and inhibitor-metal interaction.

\section{FTIR}

The composition of EPS is well established in the literature. EPS are high molecular weight mixtures of biopolymers which are mainly made up of extracellular proteins, polysaccharides (carbohydrates), and humic substances, with a small amount of uronic acid and DNA. Typically, carbohydrates have been identified as the major constituents in the EPS of many pure cultures

Peer) reviewing PDF | (2019:03:35697:1:0:NEW 2 May 2019) 
356 [21][22], whereas other researchers found relatively high protein concentrations in the sludge of

357

358

359

360

361

362

363

364

365

366

367

368

369

370

371

372

373

374

375

376

377

378

379

380

381

382

383

384

385

386

387

388

389

390

391

392

393

394

395

many wastewater treatment reactors [19].

The composition of these assorted chemicals in EPS is heavily dependent on the extraction method. Typically, the EPS extracted by heating has the highest protein concentration, followed by carbohydrates, humic acid, nucleic acid, and uronic acid [9][19][23].

The FTIR results showed that functional groups $\mathrm{O}-\mathrm{H}, \mathrm{N}-\mathrm{H}, \mathrm{C}-\mathrm{N}, \mathrm{C}=\mathrm{O}$, and $\mathrm{C}-\mathrm{H}$ were in the extracted EPS, suggesting the presence of protein, carbohydrates, humic substances, uronic acid, and DNA. Heating yields higher protein concentration, which contributes to a higher overall N-H functional group. Compared to a carbohydrate-rich mixture, a protein-rich mixture has a clear advantage due to a less drastic ratio of $\mathrm{N}-\mathrm{H}$ to other functional groups. Having more variety of functional groups in a mixture could improve the overall corrosion inhibition due to synergistic effect [24][25][26][27]. The corrosion inhibition mechanism of EPS can be inferred based on the present functional groups. They are rich in nitrogen and oxygen atoms, resembling typical organic corrosion inhibitors. Knowing that organic corrosion inhibitors are typically made up of a polar head that usually consists of nitrogen, oxygen, or sulfur atoms attached to a non-polar hydrocarbon chain, it can be deduced that the observed functional groups had contributed to the overall corrosion inhibition of carbon steel in $25^{\circ} \mathrm{C} \mathrm{CO}_{2}$ saturated $3.64 \% \mathrm{NaCl}$ solution.

Based on the basic corrosion theory, corrosion is a redox reaction. Slowing down either the reduction or oxidation reaction in a corrosion system can slow down the overall corrosion rate. The corrosion inhibition mechanism of EPS can be explained by the adsorption of various chemical compounds (corrosion inhibitors) on the metal surface. The functional groups rich in nitrogen and oxygen atoms acted as the polar head of organic corrosion inhibitors, adsorbing on the metal surface, while the non-polar hydrocarbon chain attached to the polar head isolated the metal surface from its corrosive surrounding, forming a protective biofilm. The biofilm reduced the oxidation of metal, thus reducing the overall corrosion rates.

\section{Conclusions}

In this study, WAS and EPS extracted from WAS were tested as corrosion inhibitors. Non-heattreated WAS did not inhibit corrosion at any of the evaluated concentrations. The heat treated (EPS extracted) WAS showed a corrosion inhibition performance of approximately $80.0 \%$, which compares favorably with commercial corrosion inhibitors. Developing a corrosion inhibitor using a readily available source such as WAS is an example of waste conversion to a value-added product. It could add value to WAS and in combination with the generation of other products from WAS to transform the economy efficiency of wastewater treatment operations. Based on the results presented and the needs and requirements of corrosion protection service providers, the future direction of the current research is the following: (1) produce a corrosion inhibitor with consistent properties that can lead to consistent inhibition performance (2)

Peer) reviewing PDF | (2019:03:35697:1:0:NEW 2 May 2019) 
396

397

398

399

400

401

402

403

404

405

406

407

408

409

410

411

412

413

414

415

416

417

418

419

420

421

422

423

424

425

426

427

428

429

430

431

432

433

434

435

436

437

438

439

440

reformulate a corrosion inhibitor mixture based on EPS composition that requires a lower inhibitor concentration. This could be done by blending one compound from each major chemical group present in natural EPS, namely protein, carbohydrate, humic acid, nucleic acid, and uronic acid. Compound selection can be done by prioritizing those that have previously been studied as effective corrosion inhibitors or those containing chemical groups favoring inhibition performance, such as compounds with nitrogen, oxygen, or sulfur atoms, bigger molecular structures, and longer hydrocarbon tails.

\section{References}

[1] C. W. Capuco, Waste not want not: The rise of resource recovery, Water and Wastewater International. http://www.waterworld.com/articles/wwi/print/volume-28/issue-5/regionalspotlight-us-caribbean/waste-not-want-not-the-rise-of-resource-recovery.html (accessed 17 February 2019).

[2] Resource recovery roadmaps, Water Environment Federation. https://www.wef.org/resources/topics/browse-topics-o-z/resource-recovery-roadmaps/ (accessed 17 Febraury 2019).

[3] S. Lin, Y. Wang, J. Lin, X. Wang, H. Gong, Dominant bacteria correlated with elimination of sludge in an innovative reactor, Prog. Nat. Sci. 19 (2009) 1765-1771. doi:10.1016/J.PNSC.2009.07.008.

[4] R. Stadler, W. Fuerbeth, K. Harneit, M. Grooters, M. Woellbrink, W. Sand, First evaluation of the applicability of microbial extracellular polymeric substances for corrosion protection of metal substrates, Electrochim. Acta. 54 (2008) 91-99. doi:http://dx.doi.org/10.1016/j.electacta.2008.04.082.

[5] A. Jayaraman, E. T. Cheng, J. C. Earthman, T. K. Wood, Importance of biofilm formation for corrosion inhibition of SAE 1018 steel by axenic aerobic biofilms, J. Ind. Microbiol. Biotechnol. 18 (1997) 396-401. doi:10.1038/sj.jim.2900396.

[6] W. Su et al., "A new insight into resource recovery of excess sewage sludge: Feasibility of extracting mixed amino acids as an environment-friendly corrosion inhibitor for industrial pickling," J. Hazard. Mater., vol. 279, pp. 38-45, Aug. 2014.

[7] Y. Liu, M. C. Lam, H. H. P. Fang, Adsorption of heavy metals by EPS of activated sludge, Water Sci. Technol. 43 (2001) 59-66. https://doi.org/10.2166/wst.2001.0340.

[8] J. Wang, Q. Li, M.-M. Li, T.-H. Chen, Y.-F. Zhou, Z.-B. Yue, Competitive adsorption of heavy metal by extracellular polymeric substances (EPS) extracted from sulfate reducing bacteria, J. Biortech. 163 (2014) 374-376. doi:10.1016/j.biortech.2014.04.073.

[9] S. Comte, G. Guibaud, M. Baudu, Relations between extraction protocols for activated sludge extracellular polymeric substances (EPS) and EPS complexation properties: Part I. Comparison of the efficiency of eight EPS extraction methods, Enzyme Microb. Technol. 38 (2006) 237-245. doi:10.1016/j.enzmictec.2005.06.016.

[10] S. Comte, G. Guibaud, and M. Baudu, "Relations between extraction protocols for activated sludge extracellular polymeric substances (EPS) and EPS complexation properties: Part I. Comparison of the efficiency of eight EPS extraction methods," Enzyme Microb. Technol., vol. 38, no. 1, pp. 237-245, 2006.

[11] M. S. Morad, Inhibition of phosphoric acid corrosion of zinc by organic onium compounds and their adsorption characteristics, J. Appl. Electrochem. 29 (1999) 619-626. https://doi.org/10.1023/A:1026445521937.

Peer) reviewing PDF | (2019:03:35697:1:0:NEW 2 May 2019) 
441

442

443

444

445

446

447

448

449

450

451

452

453

454

455

456

457

458

459

460

461

462

463

464

465

466

467

468

469

470

471

472

473

474

475

476

477

478

479

480

481

482

483

484

485

486

[12] A. Motalebi, M. Nasr-Esfahani, R. Ali, M. Pourriahi, Improvement of corrosion performance of 316L stainless steel via PVTMS/henna thin film, Prog. Nat. Sci. Mater. Int. 22 (2012) 392-400. doi:10.1016/j.pnsc.2012.10.006.

[13] M. Abdallah, Guar gum as corrosion inhibitor for carbon steel in sulfuric acid solutions, Port. Electrochim. Acta. 22 (2004) 161-175. doi: 10.4152/pea.200402161

[14] C. Ma, C. Zhou, J. Sun, Electrochemical corrosion behavior of the cobalt modified aluminide coating in $3.5 \mathrm{wt} \% \mathrm{NaCl}$ solutions, Prog. Nat. Sci. Mater. Int. 28 (2018) 85-89. doi:10.1016/j.pnsc.2018.01.009.

[15] X. Zhang, Corrosion and electrochemical behavior of as-cast Mg-5Y-7Gd-1Nd-0.5Zr magnesium alloys in 5\% NaCl aqueous solution, Prog. Nat. Sci. Mater. Int. 21 (2011) 314-321. doi:10.1016/S1002-0071(12)60063-X.

[16] T. R. Garrett, M. Bhakoo, Z. Zhang, Bacterial adhesion and biofilms on surfaces, Prog. Nat. Sci. 18 (2008) 1049-1056. doi:10.1016/j.pnsc.2008.04.001.

[17] N. Kip, J. A. van Veen, The dual role of microbes in corrosion, ISME J. 9 (2015) 542551. doi:10.1038/ismej.2014.169.

[18] Using physical methods to control microorganisms, Lumen Learning. https://courses.lumenlearning.com/microbiology/chapter/using-physical-methods-tocontrol-microorganisms/

[19] H. Liu and H. H. P. Fang, "Extraction of extracellular polymeric substances (EPS) of sludges," J. Biotechnol., vol. 95, no. 3, pp. 249-256, 2002.

[20] M. Ruiz-Hernando, E. Cabanillas, J. Labanda, and J. Llorens, "Ultrasound, thermal and alkali treatments affect extracellular polymeric substances (EPSs) and improve waste activated sludge dewatering," Process Biochem, 2015.

[21] P. Cescutti, R. Toffanin, P. Pollesello, and I. W. Sutherland, "Structural determination of the acidic exopolysaccharide produced by a Pseudomonas sp. strain 1.15," Carbohydr. Res., vol. 315, no. 1, pp. 159-168, 1999.

[22] L. Kennedy and I. W. Sutherland, "Polysaccharide lyases from gellan-producing Sphingomonas spp.," Microbiology, vol. 142, no. 4, pp. 867-872, Apr. 1996.

[23] H. H. P. Fang and X. S. Jia, "Extraction of extracellular polymer from anaerobic sludges," Biotechnol. Tech., vol. 10, no. 11, pp. 803-808, Nov. 1996.

[24] D.-Q. Zhang, Q.-R. Cai, X.-M. He, L.-X. Gao, and G.-D. Zhou, "Inhibition effect of some amino acids on copper corrosion in $\mathrm{HCl}$ solution," Mater. Chem. Phys., vol. 112, no. 2, pp. 353-358, Dec. 2008.

[25] G. Gece and S. Bilgiç, "A theoretical study on the inhibition efficiencies of some amino acids as corrosion inhibitors of nickel," Corros. Sci., vol. 52, no. 10, pp. 3435-3443, Oct. 2010.

[26] K. F. Khaled, "Corrosion control of copper in nitric acid solutions using some amino acids - A combined experimental and theoretical study," Corros. Sci., vol. 52, no. 10, pp. 32253234, Oct. 2010.

[27] N. O. Eddy, "Experimental and theoretical studies on some amino acids and their potential activity as inhibitors for the corrosion of mild steel, part 2," J. Adv. Res., vol. 2, no. 1, pp. 35-47, Jan. 2011.

Peer) reviewing PDF | (2019:03:35697:1:0:NEW 2 May 2019) 
Figure 1

Tafel plot for carbon steel in $3.64 \% \mathrm{NaCl}$ concentrated with $\mathrm{CO}_{2}$ with different concentrations of WAS at $25^{\circ} \mathrm{C}$

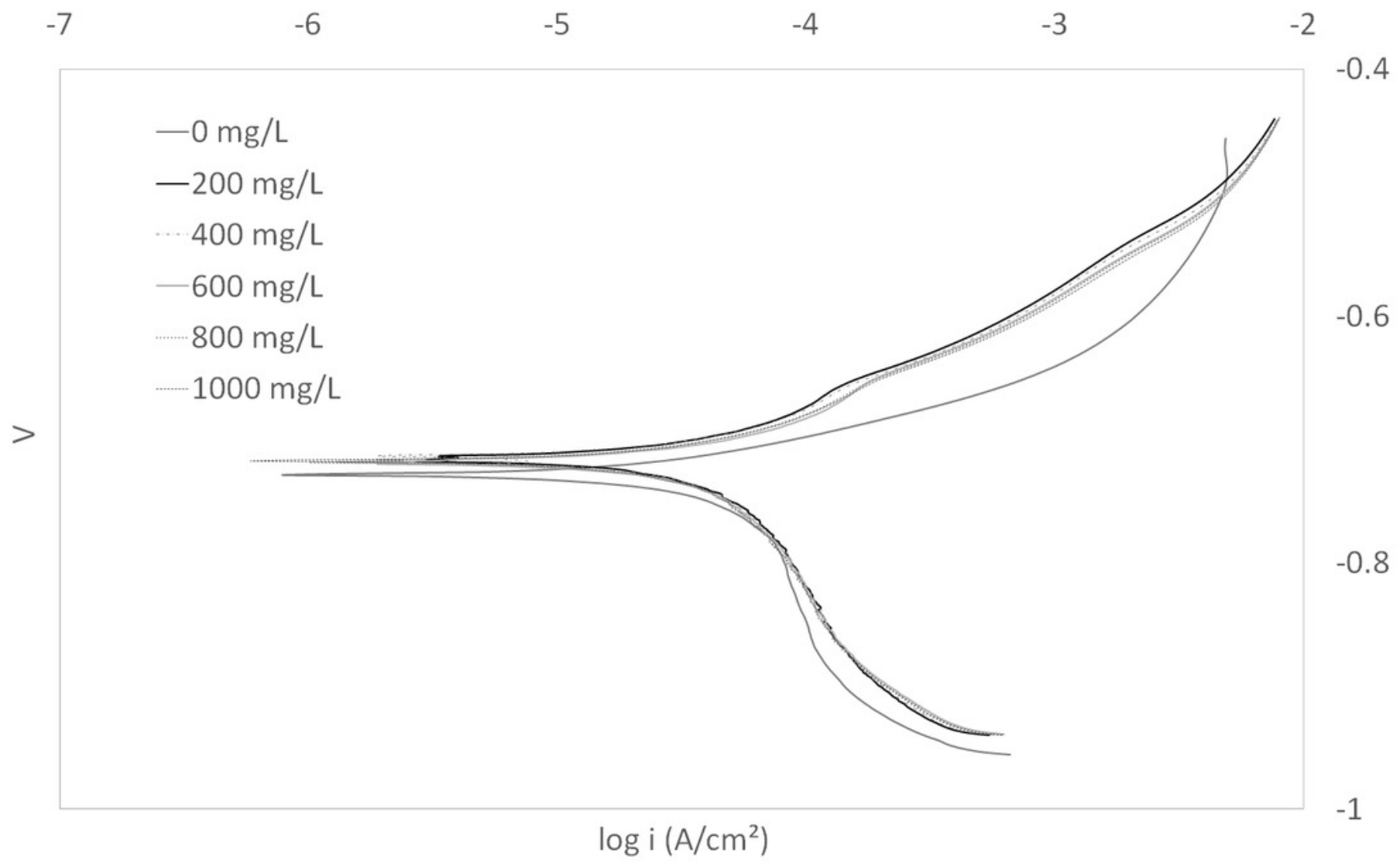


Figure 2

Tafel plot for carbon steel in $3.64 \% \mathrm{NaCl}$ concentrated with $\mathrm{CO}_{2}$ with different concentrations of EPS mixture at $25^{\circ} \mathrm{C}$

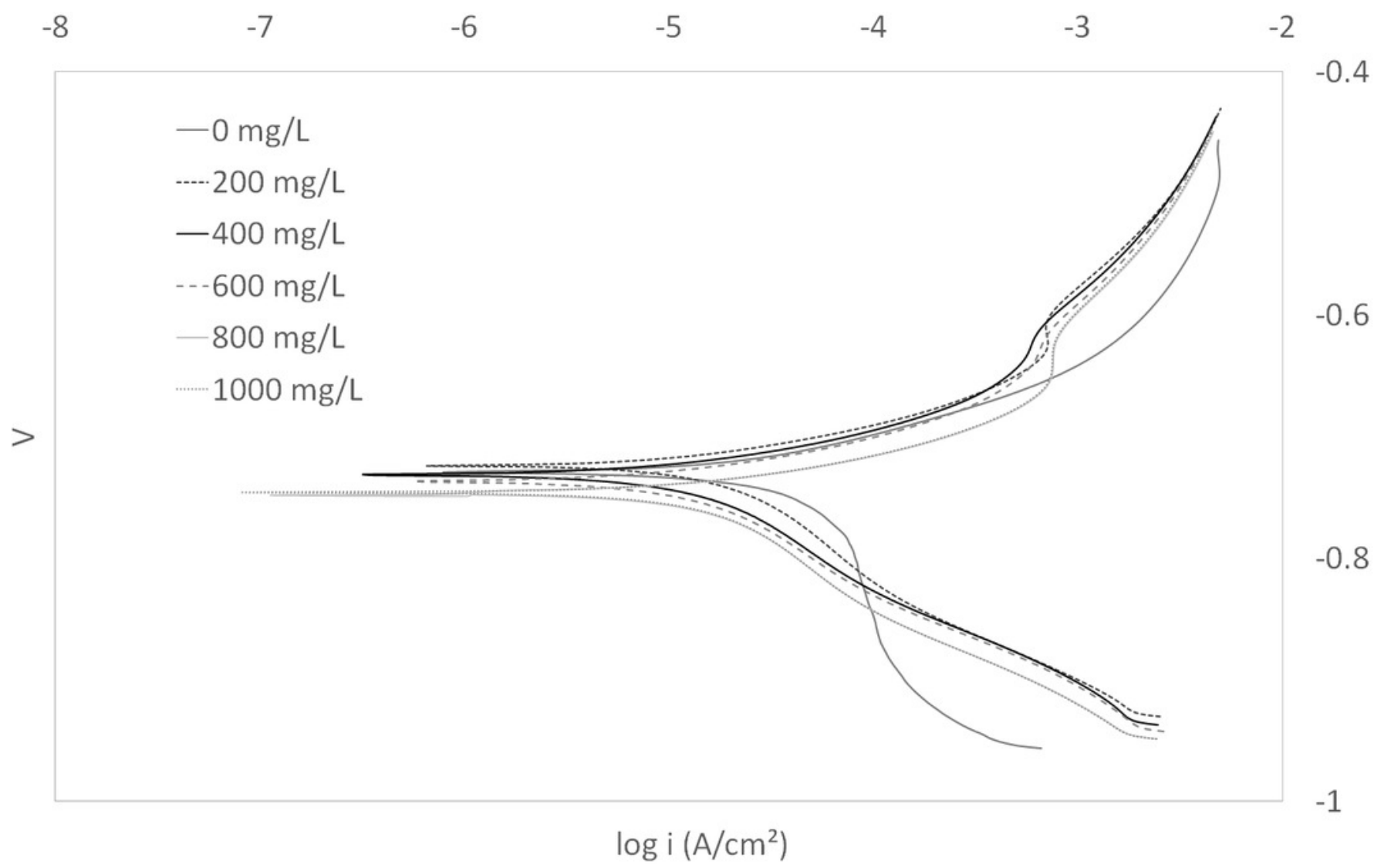


Figure 3

\section{FTIR of EPS extracted from different days}

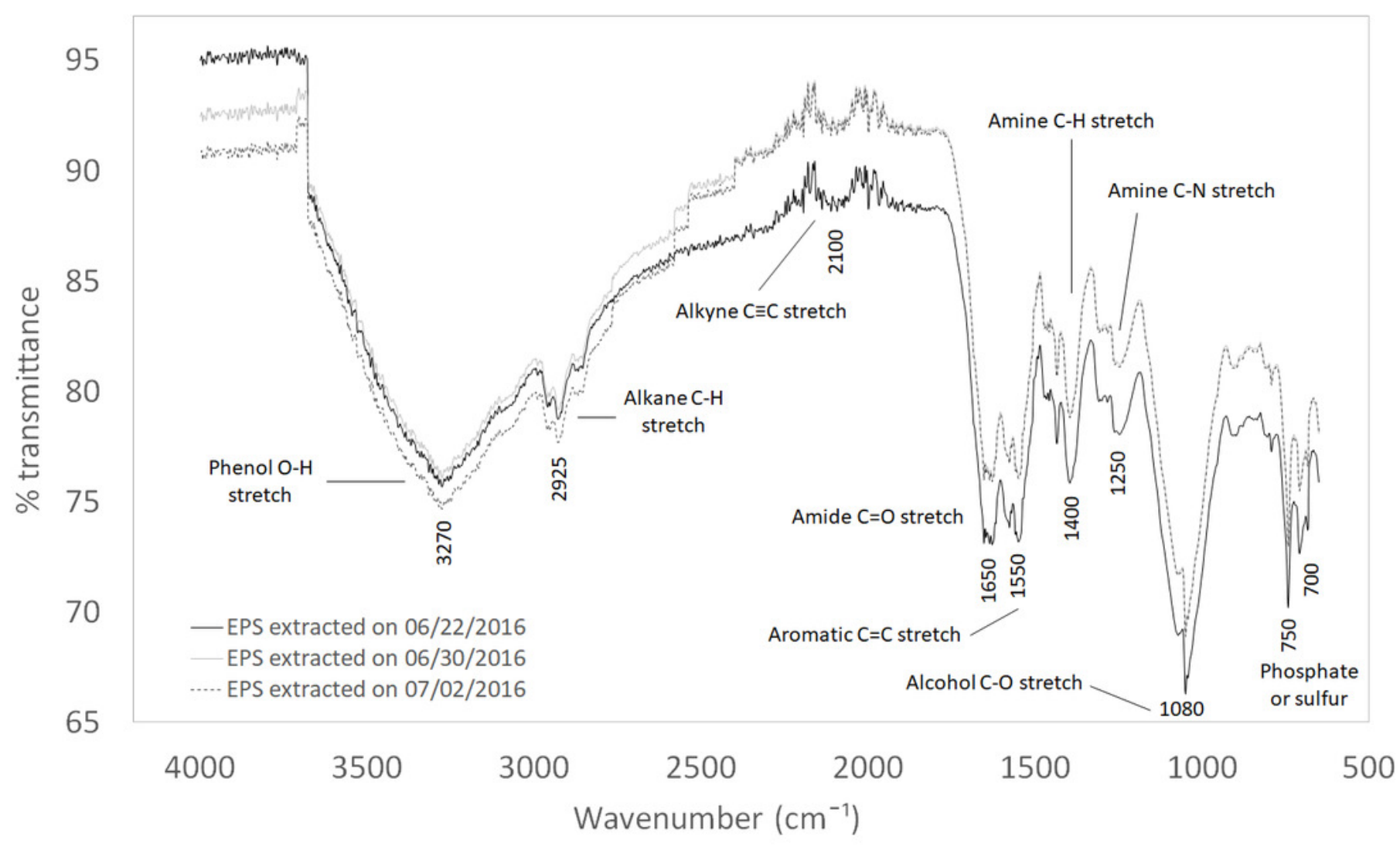




\section{Table 1 (on next page)}

Electrochemical parameters and the corresponding inhibition efficiencies of carbon steel in $3.64 \% \mathrm{NaCl}$ saturated with $\mathrm{CO}_{2}$ containing different concentrations of WAS 


\begin{tabular}{|c|c|c|c|}
\hline $\begin{array}{c}\text { Concentration } \\
(\mathrm{mg} / \mathrm{L})\end{array}$ & $\begin{array}{c}\mathrm{E}_{\text {corr }}(\mathrm{V}) \\
\text { Average } \pm \text { Standard } \\
\text { deviation }\end{array}$ & $\begin{array}{c}\mathrm{I}_{\text {corr }}\left(\mu \mathrm{A} / \mathrm{cm}^{2}\right) \\
\text { Average } \pm \text { Standard } \\
\text { deviation }\end{array}$ & $\begin{array}{c}\text { Inhibition Efficiency (\%) } \\
\text { Average } \pm \text { Standard } \\
\text { deviation }\end{array}$ \\
\hline 0 & $-0.73 \pm 0.00$ & $44.53 \pm 5.21$ & N/A \\
\hline 200 & $-0.72 \pm 0.01$ & $43.44 \pm 7.88$ & $2.86 \pm 6.90$ \\
\hline 400 & $-0.72 \pm 0.01$ & $43.44 \pm 7.88$ & $2.86 \pm 6.90$ \\
\hline 600 & $-0.72 \pm 0.01$ & $43.44 \pm 7.88$ & $2.86 \pm 6.90$ \\
\hline 800 & $-0.72 \pm 0.01$ & $43.44 \pm 7.88$ & $2.86 \pm 6.90$ \\
\hline 1000 & $-0.72 \pm 0.01$ & $43.44 \pm 7.88$ & $2.86 \pm 6.90$ \\
\hline
\end{tabular}

1 
Table 2 (on next page)

Electrochemical parameters and the corresponding inhibition efficiencies carbon steel in $3.64 \% \mathrm{NaCl}$ saturated with $\mathrm{CO}_{2}$ containing different concentrations of EPS mixture 


\begin{tabular}{|c|c|c|c|}
\hline $\begin{array}{c}\text { Concentration } \\
(\mathrm{mg} / \mathrm{L})\end{array}$ & $\begin{array}{c}\mathrm{E}_{\text {corr }}(\mathrm{V}) \\
\text { Average } \pm \text { Standard } \\
\text { Deviation }\end{array}$ & $\begin{array}{c}\mathrm{I}_{\text {corr }}\left(\mu \mathrm{A} / \mathrm{cm}^{2}\right) \\
\text { Average } \pm \text { Standard } \\
\text { Deviation }\end{array}$ & $\begin{array}{c}\text { Inhibition Efficiency (\%) } \\
\text { Average } \pm \text { Standard } \\
\text { deviation }\end{array}$ \\
\hline 0 & $-0.74 \pm 0.00$ & $46.49 \pm 3.15$ & N/A \\
\hline 200 & $-0.72 \pm 0.00$ & $15.62 \pm 0.74$ & $66.23 \pm 3.71$ \\
\hline 400 & $-0.73 \pm 0.01$ & $13.86 \pm 1.48$ & $70.00 \pm 4.78$ \\
\hline 600 & $-0.74 \pm 0.00$ & $13.56 \pm 1.76$ & $70.61 \pm 5.34$ \\
\hline 800 & $-0.75 \pm 0.01$ & $11.60 \pm 1.97$ & $74.78 \pm 5.72$ \\
\hline 1000 & $-0.75 \pm 0.01$ & $9.75 \pm 1.28$ & $78.89 \pm 3.72$ \\
\hline
\end{tabular}

1 


\section{Table 3(on next page)}

Solid and EPS contents in WAS from three samples of different days 


\begin{tabular}{|l|l|l|l|}
\hline Date & mg solid/L WAS & mg EPS/L WAS & mg EPS/g TS \\
\hline $06 / 22 / 2016$ & 7500 & 1340 & 110 \\
\hline $06 / 30 / 2016$ & 7110 & 1210 & 100 \\
\hline $07 / 02 / 2016$ & 7370 & 1270 & 110 \\
\hline Average \pm standard deviation & $7330 \pm 200$ & $1270 \pm 70$ & $110 \pm 10$ \\
\hline
\end{tabular}

1 
Table 4 (on next page)

Characteristic IR absorption frequencies of organic functional groups 


\begin{tabular}{|c|c|c|}
\hline Characteristic Absorptions $\left(\mathrm{cm}^{-1}\right)$ & Vibration Type & Functional Type \\
\hline $3200-3600$ & Phenol O-H stretch & \multirow[t]{2}{*}{$\mathrm{OH}$ into polymeric compounds } \\
\hline $2850-3000$ & Alkane C-H stretch & \\
\hline $1690-1630$ & Amide $\mathrm{C}=\mathrm{O}$ stretch & \multirow[t]{5}{*}{ Proteins } \\
\hline $1590-1650$ & Amide (I) N-H bend & \\
\hline $1500-1560$ & Amide (II) N-H bend & \\
\hline $1350-1480$ & Alkane $\mathrm{C}-\mathrm{H}$ bending & \\
\hline $1080-1360$ & Amine C-N stretch & \\
\hline$<1000$ & Several visible bands & $\begin{array}{l}\text { Phosphate or sulfur functional } \\
\text { groups }\end{array}$ \\
\hline
\end{tabular}

1 